\title{
Perancangan Jaringan Transmisi Microwave Menggunakan Passive Repeater Back to Back dan Double Flat Reflector Menggunakan PATHLOSS 5.0
}

\section{The Microwave Transmission Network Design by Passive Repeater Back to Back, Double Flat Reflector, and PATHLOSS 5.0}

\author{
Ossa Iqfirlia Zuherry ${ }^{1, *}$, Eka Setia Nugraha ${ }^{2}$, Yosy Rahmawati ${ }^{3}$ \\ ${ }^{1,2,3}$ Program Studi D3 Teknik Telekomunikasi, \\ Fakultas Teknik Telekomunikasi dan Elektro, Institut Teknologi Telkom Purwokerto \\ JL. DI Panjaitan No.128 Purwokerto, 53147, Jawa Tengah, Indonesia \\ ${ }^{1}$ Penulis korespondensi: $15201041 @$ st3telkom.ac.id \\ 2eka_nugraha@ittelkom-pwt.ac.id,
}

Received on 27-12-2018, accepted on 21-01-2019, published on 28-01-2019

\begin{abstract}
Abstrak
Menurut Badan Pusat Statistik Indonesia, jumlah penduduk Indonesia sudah mencapai 264 juta. Bertambahnya jumlah penduduk, maka bertambah pula pengguna jaringan telekomunikasi di Indonesia. Seiring dengan bertambahnya jumlah pengguna, maka pelayanan jaringan telekomunikasi juga perlu ditingkatkan. Indonesia sendiri sudah menerapkan beberapa teknologi telekomunikasi dan salah satunya adalah teknologi seluler. Pada teknologi seluler media yang digunakan adalah adalah udara berupa gelombang mikro yang biasa disebut microwave. Teknologi komunikasi radio gelombang mikro digunakan sebagai sarana transmisi antar Base Tranciever Station (BTS) atau Base System Control (BSC). Karena sinyal yang dipancarkan melalui medium udara, maka komunikasi ini rentan terhadap gangguan yang disebabkan oleh perubahan cuaca. Pada keadaan ini dapat diatasi dengan penggunaan passive repater back to back antenna, single reflector dan double flat reflector. Pada tugas akhir ini dilakukan perancangan jaringan microwave menggunakan repeater back to back dan double flat reflector dengan hoplink yang sama. Perancangan jaringan ini microwave dilakukan di Sulawesi Selatan dengan site xBantaeng terletak pada koordinat lintang selatan $05^{\circ} 29^{\circ} 07.04^{\circ} \mathrm{S}$ dan koordinat bujur timur $119^{\circ} 51^{\circ} 51.49^{\circ} \mathrm{E}$. Sedangkan site xSinjai terletak di koordinat lintang selatan $5^{\circ} 13^{\circ} 19.23^{\circ} \mathrm{S}$ dan koordinat bujur timur $120^{\circ} 4^{\circ} 32.27^{\circ} \mathrm{E}$, dan koordinat lintang selatan $5^{\circ} 21^{\circ} 21.08^{\circ} \mathrm{S}$ dan koordinat bujur timur $119^{\circ} 56^{\circ} 13.83^{\circ} \mathrm{E}$ digunakan xGunung Sari untuk penempatan repeater dan reflector. Perancangan ini menggunakan Pathloss 5.0. Nilai availability optimalnya bernilai diatas 99\%. Untuk kasus pada Tugas Akhir ini baik penggunaan repeater back to back maupun double flat reflector sama-sama mendapatkan nilai optimal. 99,95755\% untuk avilability repeater back to back dan $99,82100 \%$ untuk double flat reflector. Dengan kesimpulan penggunaan double flat reflector menghasilkan availability yang lebih baik.
\end{abstract}

Keywords: Double Flat Reflector, Microwave, Pathloss 5.0, Repeater back to back. 


\begin{abstract}
According to the Indonesian Central Statistics Agency, Indonesia's population has reached 264 million. As the population increases, the number of telecommunication network users in Indonesia also increases. Along with the increasing number of users, telecommunications network services also need to be improved. Indonesia has implemented several telecommunications technologies, one of which is cellular technology. In cellular technology, the media used is air in microwaves, commonly called microwaves. Microwave radio communication technology is used to transmit between Base Transceiver Stations (BTS) or Base System Control (BSC). Because the signal is transmitted through the air medium, this communication is vulnerable to interference caused by changes in weather. This situation can be overcome by using a passive repeater back-to-back antenna, single reflector, and double flat reflector. In this final project, a microwave network is designed using a back-to-back repeater and a double flat reflector with the same uplink. The design of this microwave network was carried out in South Sulawesi with the xBantaeng site located at south latitude coordinates $05^{\circ} 29^{\circ} 07.04^{\circ} \mathrm{S}$ and east longitude coordinates $119^{\circ}$ $51^{\circ} 51.49^{\circ} \mathrm{E}$. While the xSinjai site is located at south latitude coordinates $5^{\circ} 13^{\circ} 19.23^{\circ} \mathrm{S}$ and east longitude coordinates $120^{\circ} 4^{\circ} 32.27^{\circ} \mathrm{E}$, and south latitude coordinates of $5^{\circ} 21^{\circ}$ $21.08^{\circ} \mathrm{S}$ and east longitude coordinates of $119^{\circ} 56^{\circ} 13.83^{\circ} \mathrm{E}$ are used by xGunung Sari for the placement of repeaters and reflectors. This design uses Pathloss 5.0. Therefore, the optimal availability value is above $\mathbf{9 9 \%}$. For the case in this Final Project, both back-to-back repeaters and double flat reflectors get optimal values. $99.95755 \%$ for repeater availability back to back and $99.82100 \%$ for the double flat reflector. In conclusion, using a double flat reflector results in better availability.
\end{abstract}

Keywords: Double Flat Reflector, Microwave, Pathloss 5.0, Repeater back to back.

\title{
I. Pendahuluan
}

Menurut Badan Pusat Statistik Indonesia, jumlah penduduk Indonesia sudah mencapai 264 juta. Bertambahnya jumlah penduduk, maka bertambah pula pengguna jaringan telekomunikasi di Indonesia. Perkembangan pengguna ini juga mempengaruhi perkembangan teknologi telekomunikasi di Indonesia. Seiring dengan bertambahnya jumlah pengguna, maka pelayanan jaringan telekomunikasi juga perlu ditingkatkan. Indonesia sendiri sudah menerapkan beberapa teknologi telekomunikasi dan salah satunya adalah teknologi seluler. Pada teknologi seluler media yang digunakan adalah adalah udara berupa gelombang mikro yang biasa disebut microwave.

Teknologi komunikasi radio gelombang mikro digunakan sebagai sarana transmisi antar Base Tranciever Station (BTS) atau Base System Control (BSC). Karena sinyal yang dipancarkan melalui medium udara, maka komunikasi ini rentan terhadap gangguan yang disebabkan oleh perubahan cuaca. Selain itu keadaan kontur di Indonesia yang merupakan negara dengan banyak gunung maupun bukit, yang menyebabkan kondisi permukaan tanah tingginya tidak sama. Adanya gunung maupun bukit tersebut menyebabkan komunikasi yang dikirim tidak sampai sepenuhnya kepada penerima. Gangguan komunikasi ini disebut dengan multipath fading yaitu adanya objek penghalang antara hoplink pengirim dan penerima. Karena gangguan ini maka pengguna akan merasa dirugikan dengan tidak stabilnya layanan jaringan yang diberikan.

Pada keadaan ini dapat diatasi dengan penggunaan passive repater. Passive repeater terdiri dari tiga macam yaitu back to back antenna, single reflector, dan double flat reflector. Passive repeater back to back antenna terdiri dari dua antena yang dihubungkan oleh sebuah kabel secara back to back. Pada kedua antena tersebut biasanya menggunakan antena dengan diameter besar. Sedangkan, untuk double flat reflector terdiri dari dua lembar besar, datar, persegi panjang, dan hampir sejajar satu sama lain dengan sudut $45^{\circ}$ atau lebih antara sinar microwave dan permukaan reflektor. Penggunaan repeater ini dapat mengatasi masalah adanya obstacle yang menghalangi hoplink microwave, seperti puncak gunung yang tidak dapat diakses dengan aktif repeater. Jadi, atas dasar diatas penulis mengambil lokasi site x Bantaeng dan site xSinjai, dikarenakan kedua site tersebut tidak Line of Sight (LOS).

Sehingga atas dasar tersebut, penulis mengambil judul "PERANCANGAN JARINGAN TRANSMISI MICROWAVE MENGGUNAKAN PASSIVE REPEATER BACK TO BACK DAN DOUBLE FLAT 
REFLECTOR MENGGUNAKAN PATHLOSS 5.0". Penulis bermaksud membuat simulasi perancangan jaringan microwave menggunakan passive repeater back to back antena dan double flat reflector menggunakan pathloss 5.0. Hasil dari dua perancangan tersebut akan dibandingkan hasilnya dengan menampilkan parameter berupa Availability, Unavailability, Free Space Loss, EIRP, RSL, fading margin dari hasil report simulasi Pathloss 5.0 dan perhitungan link budget.

\section{Metode Penelitian}

Metode penelitian yang digunakan pada penelitian ini yaitu meliputi:

Studi kasus merupakan metode penelitian yang digunakan oleh penulis dalam pengerjaan Tugas Akhir. Studi kasus dilakukan di PT. Alita Mitra Praya. Untuk melengkapi materi penelitian dibutuhkan data yang sesuai objek penelitian. Data yang didapat penulis berupa data latitude dan longitude sebagai parameter pada site xSinjai, site xBantaeng, dan site xGunung Sari untuk perancangan jaringan transmisi microwave pada Pathloss 5.0. Pada studi literatur yang dilakukan penulis dalam proses pengerjaan Tugas Akhir ini adalah dengan mencari data materi yang berhubungan dengan masalah yang dibahas melalui beberapa referensi, seperti buku, jurnal ilmiah, dan internet.

Pada metode perancangan dilakukan perancangan jaringan microwave untuk site xSinjai, site xBantaeng, dan site xGunung Sari menggunakan Pathloss 5.0. pada perancangan jaringan microwave hal yang dilakukan terlebih dahulu adalah memasukkan koordinat latitude dan longitude, untuk nilai elevasi dapat dilihat pada Google Earth dan untuk parameter lain dapat disesuaikan dengan nilai yang dibutuhkan berdasarkan perhitungan link budget seperti nilai tinggi antena, diameter antena, frekuensi kerja, dan lainlain.

Kemudian setelah perancangan hoplink selesai, penulis akan mengamati hasil report. Dan apabila hasil yang didapatkan tidak sesuai dengan yang diinginkan maka dilakukan perancangan lagi dengan menambahkan repeater atau reflektor, atau bisa juga mengganti parameter-parameter yang sudah disesuaikan. Adapun diagram alur atau flowchart dapat dilihat pada gambar 1. 


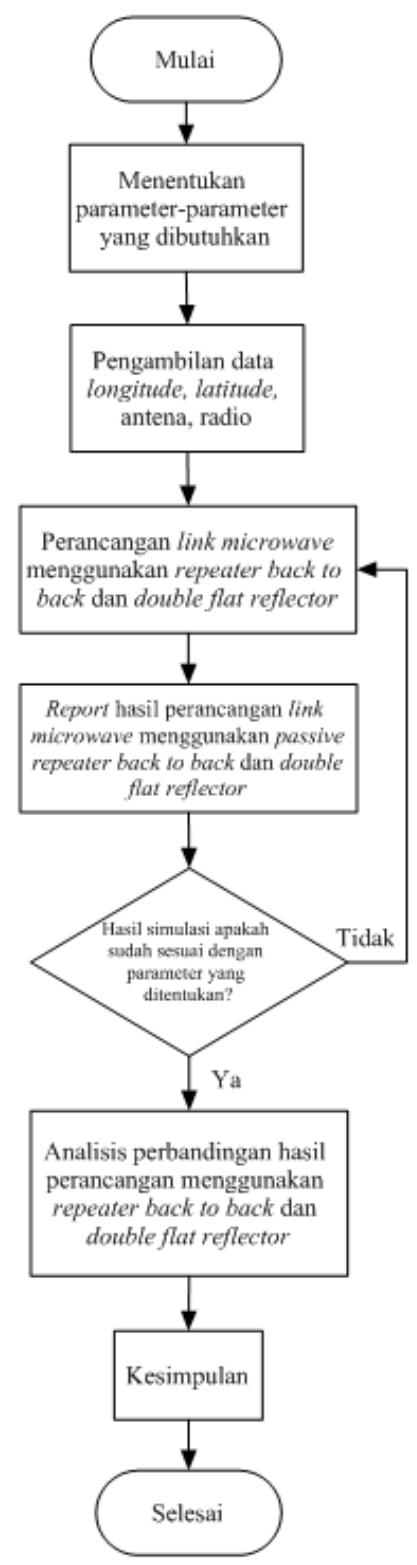

Gambar 1. Flowchart perancangan jaringan transmisi microwave

Analisa ini dilakukan dari hasil studi kasus hoplink antara site xBantaeng dan xSinjai dalam keadaan tidak Line of Sight (LOS) karena ada penghalang berupa bukit setinggi 2000 mdpl. Jadi perlu ditambahkan adanya repeater back to back maupun double flat reflector. Hasil yang diharapkan penulis adalah mengetahui penggunaan repeater atau reflector yang lebih baik pada kasus ini.

Jadi penulis akan menampilkan hasil dari repeater back to back dan double flat reflector. Dengan melihat parameter gain antenna, free space loss, fading margin, EIRP, availability, dan unavailability.

\section{HASIL DAN PEMBAHASAN}

Perancangan tanpa passive repeater adalah perancangan yang dilakukan pada site xBantaeng menuju site xSinjai. Perancangan ini dilakukan pada daerah not LOS dengan jarak antar site adalah $36,70 \mathrm{~km}$. Untuk titik koordinat xBantaeng berada pada koordinat lintang selatan $5^{\circ} 29^{\circ} 07.05^{\circ} \mathrm{S}$ dan koordinat bujur timur $119^{\circ} 51^{\circ} 51.49^{\circ} \mathrm{E}$ dengan elevasi $650,4 \mathrm{~m}$, sedangkan untuk site xSinjai berada pada koordinat lintang 
selatan $5^{\circ} 13^{\circ} 18.64^{\circ} \mathrm{S}$ dan bujur timur $120^{\circ} 04^{\circ} 24.25^{\circ} \mathrm{E}$ dengan elevasi $433,4 \mathrm{~m}$. Agar perancangan jaringan transmisi microwave pada link site xBantaeng - xSinjai dapat bekerja optimal maka diperlukan perhitungan link budget untuk melihat kesesuaian hasil antara report pathloss 5.0 dan hasil perhitungan link budget.

\section{Jalur Transmisi}

Jalur transmisi adalah jarak antar BTS yang dihitung dengan cara menentukan posisi nominal dua titik pada garis bumi dan menghitung jaraknya. Jarak antara site xBantaeng dan site xSinjai dapat dihitung menggunakan persamaan berikut dengan mengkonversi garis lintang dan garis bujur dari masing-masing koordinat site seperti berikut ini:

a. Konversi lintang dan bujur pada site xBantaeng yang terletak pada lintang selatan $5^{\circ} 29^{\circ} 07.05^{\circ} \mathrm{S}$ dan koordinat bujur timur $119^{\circ} 51^{\circ} 51.49^{\circ} \mathrm{E}$

Garis lintang dan bujur $=$ derajat $+\frac{\text { menit }}{60}+\frac{\text { detik }}{3600}$

Garis Lintang $=5+\frac{29}{60}+\frac{7,4}{3600}=5,49^{\circ}$

Garis Bujur $=119+\frac{51}{60}+\frac{51,49}{3600}=119,86^{\circ}$

b. Konversi lintang dan bujur pada site xSinjai yang terletak pada lintang selatan $5^{\circ} 13^{\circ} 18.64^{\circ} \mathrm{S}$ dan bujur timur $120^{\circ} 04^{\circ} 24.25^{\circ} \mathrm{E}$

Garis Lintang $=5+\frac{13}{60}+\frac{18,64}{3600}=5,22^{\circ}$

Garis Bujur $=120+\frac{4}{60}+\frac{24,25}{3600}=120,07^{\circ}$

Untuk menentukan jarak antara kedua site, maka digunakan persamaan berikut. Namun sebelum itu dihitung terlebih dahulu jarak lintang kedua site dan jarak bujur kedua site seperti berikut:

Jarak lintang $=\mid$ Garis lintang BTS1-Garis lintang BTS2 $\mid$ x 110,32

Jarak bujur $=\mid$ Garis Bujur BTS1-Garis Bujur BTS2 $\mid \times 111,32$

Maka jarak antar BTS (Pathlength) adalah

$$
\begin{aligned}
& \text { Pathlength }=\sqrt{(\text { jarak lintang })^{2}+(\text { jarak bujur })^{2}} \\
& \text { Jarak lintang }=|5,49-5,22| x 110,32=29,79 \mathrm{~km} \\
& \text { Jarak bujur }=|119,86-5,22| x 111,32=23,38 \mathrm{~km} \\
& \text { Pathlength }=\sqrt{(29,79)^{2}+(23,38)^{2}}=37,86 \mathrm{~km}
\end{aligned}
$$

Berdasarkan hasil dari report pathloss 5.0 jarak site antara xBantaeng dengan xSinjai adalah $36,70 \mathrm{~km}$, sedangkan hasil perhitungan link budget adalah $37,86 \mathrm{~km}$.

\section{Gain Antena}

Gain antena merupakan kemampuan mengukur antena untuk mengirimkan gelombang yang diinginkan ke arah tujuan. Parameter jenis antena yang digunakan pada perancangan jaringan transmisi microwave pada site xBantaeng maupun site xSinjai memiliki diameter 3,66 m dengan efisiensi 50\%. Frekuensi yang adalah $13 \mathrm{GHz}$, sehingga besarnya nilai gain antena dapat dihitung seperti berikut:

$$
\text { Gain }=20 \log f_{G H z}+20 \log d_{\text {meter }}+10 \log \eta+20,4
$$




$$
\text { Gain }=20 \log 13+20 \log 3,66+10 \log 0,5+20,4=50,94 d B
$$

Berdasarkan hasil dari report pathloss 5.0 nilai gain antara xBantaeng dengan xSinjai adalah 50,90 dB, sedangkan hasil perhitungan link budget adalah 50,94 dB.

\section{Free Space Loss (FSL)}

Free space loss adalah redaman yang ada sepanjang ruang antara antena pemancar dan penerima. Pada ruang ini tidak diijinkan adanya penghalang, karena transmisinya sendiri berkarakter LOS. Redaman ruang bebas atau free space loss dipengaruhi oleh jarak antara kedua site dan frekuensi yang digunakan. Pada perencanaan ini dengan frekuensi $13 \mathrm{GHz}$ dan jarak antara kedua site $37,86 \mathrm{~km}$ didapatkan nilai free space loss sebagai berikut:

$$
\begin{aligned}
F S L & =92,45+20 \log \log f_{G H z}+20 \log D_{k m} \\
F S L & =92,45+20 \log \log 13+2 \log \log 37,86 \\
& =146,29 d B
\end{aligned}
$$

Berdasarkan hasil dari report pathloss 5.0 nilai free space loss antara xBantaeng dengan xSinjai adalah 146,04 dB, sedangkan hasil perhitungan link budget adalah 146,29 dB.

\section{Effective Isotropic Radiated Power (EIRP)}

EIRP merupakan daya maksimum gelombang sinyal mikro yang keluar dari antena pemancar atau untuk menunjukan nilai efektif daya yang dipancarkan antena pemancar, dalam arti lain daya tersebut sudah mengalami penguatan. EIRP adalah daya pancar yang keluar dari site yang nilainya dipengaruhi oleh daya pancar antena pemancar, penguatan/gain, dan rugi-rugi yang dihasilkan dari site xBantaeng. Rugi-rugi yang dihasilkan termasuk loss feeder, connector loss, branching loss dan loss atmosfer.

$$
\begin{aligned}
E I R P & =P_{T x}+G_{T x}-L_{T X}(2.5) \\
E I R P & =21+50,94-(6,67+0,5+2+0,75) \\
& =62,02 \mathrm{dBm}
\end{aligned}
$$

Besarnya EIRP pada site xSinjai masih menggunakan rumus yang sama seperti berikut:

$$
\begin{aligned}
E I R P & =P_{T x}+G_{T x}-L_{T X} \\
\text { EIRP } & =21+50,90-(6,78+0,5+2+0,75) \\
& =61,91 \mathrm{dBm}
\end{aligned}
$$

Berdasarkan hasil dari report pathloss 5.0 nilai EIRP site xBantaeng adalah 64,73 dBm sedangkan perhitungan link budget adalah $62,02 \mathrm{dBm}$. Untuk nilai site xSinjai adalah $64,62 \mathrm{dBm}$, sedangkan hasil perhitungan link budget adalah $61,91 \mathrm{dBm}$. Keduanya memiliki nilai berbeda karena memiliki nilai TX line loss yang berbeda, nilai ini berbeda disebabkan panjang kabel feeder yang digunakan kedua site tersebut berbeda. Untuk site xBantaeng menggunakan panjang kabel feeder 58 meter, sedangkan site xSinjai 59 meter. 


\section{Isotropic Received Level (IRL)}

Isotropic Received Level (IRL) merupakan nilai level daya isotropik yang diterima oleh stasiun penerima. Besarnya nilai IRL dipengaruhi oleh EIRP dan free space loss. Nilai IRL akan digunakan untuk mencari level daya terima yang dihasilkan pada site penerima. Berdasarkan perhitungan sebelumnya nilai EIRP pada site xBantaeng adalah $61,98 \mathrm{~dB}$ dan EIRP pada site xSinjai adalah 61,87 dB. Dengan menggunakan rumus maka didapatkan nilai IRL pada site xBantaeng sebagai berikut:

$$
\begin{aligned}
I R L & =E I R P-F S L \\
I R L & =62,02-146,29 \\
& =-84,27 \mathrm{dBm}
\end{aligned}
$$

Dengan menggunakan persamaan yang sama didapatkan nilai IRL pada site xSinjai sebagai berikut:

$$
\begin{aligned}
I R L & =E I R P-F S L \\
I R L & =61,91-146,29 \\
& =-84,38 \mathrm{dBm}
\end{aligned}
$$

Nilai IRL tidak ada pada report pathloss 5.0, jadi nilai IRL digunakan untuk mencari nilai RSL.

\section{6. $\quad$ Received Signal Level (RSL)}

Received Signal Level (RSL) merupakan level daya yang diterima oleh piranti pengolah decoding. Level daya terima atau RSL dipengaruhi oleh IRL, gain antena, dan rugi-rugi yang dihasilkan pada site penerima termasuk loss feeder, loss connector, branching loss dan loss atmosfer. Hasil perhitungan RSL pada site xBantaeng adalah sebagai berikut:

$$
\begin{aligned}
R S L & =I R L+G_{R X}-L_{R X} \\
R S L & =-84,27+50,94-(6,67+0,5+2+0,75) \\
& =-43,25 \mathrm{dBm}
\end{aligned}
$$

Dengan menggunakan persamaan yang sama didapatkan nilai RSL pada site xSinjai sebagai berikut:

$$
\begin{aligned}
R S L & =I R L+G_{R X}-L_{R X} \\
R S L & =-84,38+50,94-(6,78+0,5+2+0,75) \\
& =-43,25 \mathrm{dBm}
\end{aligned}
$$

Nilai yang didapatkan dengan perhitungan link budget nilai $-43,25 \mathrm{dBm}$. Nilai RSL yang didapatkan pada pathloss 5.0 adalah $-38,43 \mathrm{dBm}$. Nilai ini termasuk nilai yang buruk, dikarenakan adanya penghalang diantara link transmisi microwave sehingga menyebabkan gelombang radio yang dipancarkan memantul dan tidak sampai di penerima sepenuhnya.

\section{Fading Margin}

Fading margin merupakan persamaan perhitungan, untuk mendapatkan nilai fading margin yaitu dengan memasukan received signal level dan nilai threshold pada sisi penerima. Fading margin digunakan sebagai cadangan daya untuk mempertahankan level sinyal terima tetap berada diatas batas ambang daya terima 
(threshold). Fading margin dipengaruhi oleh besarnya nilai threshold dan level daya terima. Untuk mendapatkan nilai fading margin dapat dihitung menggunakan persamaan seperti sebagai berikut:

$$
\begin{aligned}
F M & =R S L-R_{X t h} \\
F M & =-43,25-(-93) \\
& =49,75 \mathrm{~dB}
\end{aligned}
$$

Berdasarkan hasil perhitungan dengan RSL yang didapatkan dari perhitungan sebelumnya dan nilai $\mathrm{Rx}_{\text {threshold }}$ yang didapatkan dari datasheet radio microwave yang digunakan yaitu MicroStar $\mathrm{M} / \mathrm{H} 13 \mathrm{I}$ didapatkan nilai fading margin sebesar 49,75 dB. Sedangkan dari hasil perancangan menggunakan Pathloss 5.0 didapatkan nilai fading margin sebesar $54,57 \mathrm{~dB} \mathrm{dBm}$. Nilai fading margin yang dihasilkan sangat buruk karena diharapkan nilai fading margin yang didapatkan sebesar-besarnya untuk digunakan sebagai cadangan daya.

\section{Unavailability}

Nilai unavailability sistem transmisi microwave dipengaruhi oleh faktor kekasaran bumi, faktor iklim, frekuensi kerja yang digunakan, jarak antara kedua site dan fading margin. Site xBantaeng dan site xSinjai berada didaerah pegunungan sehingga nilai faktor kekasaran bumi yang digunakan yaitu 1/4, sedangkan faktor iklim untuk daerah pegunungan yaitu sebesar 1/8. Dengan menggunakan persamaan berikut didapatkan nilai unavilability untuk site xBantaeng - xSinjai sebagai berikut:

$$
\begin{aligned}
U n A v & =a \times b \times 2,5 \times f_{G H z} \times D_{k m}^{3} \times 10^{-6} \times 10^{-\frac{F M}{10}} \\
U n A v & =0,25 \times 0,125 \times 2,5 \times 13 \times 37,86^{3} \times 10^{-6} \times 10^{-\frac{49,75}{10}} \\
& =51082,9 \%
\end{aligned}
$$

Berdasarkan hasil perhitungan, nilai unavaibility yang dihasilkan yaitu 51082,9\%. Nilai ini termasuk sangat tinggi untuk indikator ketidakhandalan sistem transmisi microwave, idealnya nilai unavaibility adalah kurang dari 1 .

\section{Avaibility}

Nilai availability dipengaruhi oleh nilai unavailability. Nilai availability atau kehandalan sistem transmisi microwave ini memiliki satuan \%. Untuk mendapatkan nilai availabily dapat dihitung menggunakan persamaan 2.11 seperti berikut:

$$
\begin{aligned}
A v & =(1-U n A v) \times 100 \% \\
A v & =(1-51082,9) \times 100 \% \\
& =-51081,9 \%
\end{aligned}
$$

Berdasarkan hasil perhitungan, nilai availability yang dihasilkan $-51081,9 \%$. Nilai ini sangat buruk sekali untuk sistem transmisi microwave yang idealnya harus mencapai 99\%. Sehingga perencanaan sistem transmisi microwave dari site xBantaeng menuju site xSinjai tanpa repeater tidak dapat diimplementasikan karena terdapat penghalang yang menghasilkan nilai kehandalan sistem yang sangat buruk.

Hasil dari perancangan menggunakan pathloss 5.0 untuk site xBantaeng menuju site xSinjai didapatkan bahwa sistem transmisinya tidak Line of Sight (LOS) dikarenakan adanya penghalang berupa bukit yang berada pada kedua site. Dari hasil diatas dapat dilihat bahwa site xBantaeng dan site xSinjai tidak berada 
pada daeral LOS, oleh karena itu perlu ditambahkan repeater dan reflector berada pada koordinat lintang selatan $5^{\circ} 21^{\circ} 21.08^{\circ} \mathrm{S}$ dan bujur timur $119^{\circ} 56^{\circ} 13.83^{\circ} \mathrm{E}$ dengan elevasi $2806,6 \mathrm{~m}$.

Perancangan yang menggunakan back to back antenna ini membutuhkan penggabungan dari site $\mathrm{xBantaeng}$ menuju site repeater dan site repeater menuju site xSinjai. Perancangan ini menggunakan repeater back to back yang memiliki dua buah antena yang dipasang secara back to back dan berfungsi untuk melewatkan sinyal. Dari hasil pathloss 5.0 didapatkan gain antena sebesar 50,90 dBi. Dengan jarak $37,60 \mathrm{~km}$ dan frekuensi sebesar $13 \mathrm{GHz}$ menghasilkan nilai FSL 280,46 dB. Passive gain yang dihasilkan adalah 101,24 dB ini merupakan nilai dari gain dar pasif repeater repeater yang digunakan. Memiliki Ptx sebesar $21 \mathrm{dBm}$, Tx line loss yang masing-masing 6,67 dan 6,78, connector loss $0,5 \mathrm{~dB}$, branching loss 2 $\mathrm{dB}$, dan atmp loss $0,77 \mathrm{~dB}$ mendapatkan nilai EIRP xBantaeng adalah 64,73 sedangkan untuk site xSinjai 64,62. Fading margin yang dihasilkan bernilai $21,37 \mathrm{~dB}$ dan nilai optimal yang didapatkan setelah menambahkan repeater back to back ini adalah 99,95755\% nilai dapat dikatakan optimal karena sudah berada diatas nilai $99 \%$ dan nilai unavailability yang didapatkan adalah $0,04245 \%$.

Perancangan double flat reflector ini juga membutuhkan penggabungan dari site xBantaeng menuju site repeater dan site repeater menuju site xSinjai. Perancangan ini menggunakan sebuah reflector yang memiliki luas sebesar 2,43 m x 3,04 m. Dari hasil pathloss 5.0 didapatkan gain antena sebesar 50,90 dBi. Dengan jarak 37,60 km dan frekuensi sebesar $13 \mathrm{GHz}$ menghasilkan nilai FSL 280,46 dB. Passive gain yang dihasilkan adalah 103,82 dB ini merupakan nilai dari gain dari pasif repeater yang digunakan. Memiliki Ptx sebesar $21 \mathrm{dBm}$, Tx line loss yang masing-masing 6,67 dan 6,78, connector loss 0,5 dB, branching loss $2 \mathrm{~dB}$, dan atmp loss $0,77 \mathrm{~dB}$ mendapatkan nilai EIRP untuk xBantaeng dan xSinjai adalah $61,89 \mathrm{dBm}$. Fading margin yang dihasilkan bernilai $23,94 \mathrm{~dB}$ dan nilai availability yang didapatkan setelah menambahkan double flat reflector ini adalah 99,82100\% dan nilai unavailability yang didapatkan adalah $0,179 \%$.

Tabel 1 Hasil Perbandingan berdasarkan perhitungan link budget

\begin{tabular}{|c|c|c|}
\hline Parameter & Repeater Back to Back & Double Flat Reflector \\
\hline Passive Gain $(\mathrm{dB})$ & 101,32 & 104,72 \\
\hline Received Signal Level $(\mathrm{dBm})$ & $-75,62$ & $-72,98$ \\
\hline Fading Margin $(\mathrm{dB})$ & 17,38 & 19,8 \\
\hline Unavailability (\%) & $3,44 \times 10^{-4}$ & $5,06 \times 10^{-4}$ \\
\hline Availability (\%) & 99,96562 & 99,94938 \\
\hline
\end{tabular}

Berdasarkan tabel 1 jaringan transmisi microwave antara site xBantaeng dan xSinjai walaupun memiliki parameter-parameter yang sama seperti jarak yaitu $36,70 \mathrm{~km}$, frekuensi $13 \mathrm{GHz}$, gain antena 50,94 dB, dan parameter lain yang sama. Tetapi memiliki nilai passive gain, RSL, FM, unavilability, dan availability yang berbeda.

Nilai passive gain antara back to back dan double flat reflector berbeda karena, pada repeater back to back dihasilkan dari kedua antena yang dipasang secara back to back. Sedangkan pada double flat reflector, gain dihasilkan dari luas permukaan bidang reflektor sebesar 2,43 m x 3,04 m.

Nilai RSL juga mendapatkan nilai yang berbeda, dengan nilai RSL pada back to back antena lebih besar dengan nilai -75,62 dBm dan -72,98 dBm untuk double flat reflector. Perbedaan ini dipengaruhi oleh nilai gain passive, dimana untuk repeater menggunakan gain repeater begitu juga untuk reflector menggunakan gain reflector. Jadi untuk nilai RSL semakin besar nilai RSL maka semakin baik kualitas layanan jaringan transmisi microwave tersebut.

Untuk nilai fading margin sendiri dipengaruhi oleh RSL. FM merupakan cadangan daya yang digunakan agar dapat mempertahankan level sinyal terima diatas level batas ambang atau threshold. Semakin besar nilai FM maka semakin baik pula layanan yang diberikan oleh suatu sistem, karena cadangan daya yang dihasilkan semakin besar. Jadi untuk FM penggunaan double flat reflector lebih baik daripada back to back pada site xBantaeng menuju site xSinjai.

Pada kehandalan sistem atau availability idelanya bernilai diatas 99\%. Untuk kasus pada Tugas Akhir ini baik penggunaan repeater back to back maupun double flat reflector sama-sama mendapatkan nilai optimal, karena sudah berada diatas 99\%. Tetapi, penggunaan back to back antenna bernilai lebih besar daripada double flat reflector. 
Tabel 2 Hasil Perbandingan Berdasarkan Pathloss 5.0

\begin{tabular}{|c|c|c|}
\hline Parameter & Repeater Back to Back & Double Flat Reflector \\
\hline Passive Gain $(\mathrm{dB})$ & 101,24 & 103,82 \\
\hline Received Signal $(\mathrm{dBm})$ & $-71,52$ & $-69,06$ \\
\hline $\begin{array}{c}\text { Thermal Fading Margin } \\
(\mathrm{dB})\end{array}$ & 21,48 & 23,94 \\
\hline $\begin{array}{c}\text { Worst month multipath } \\
\text { availability (\%) }\end{array}$ & 99,95866 & 99,82100 \\
\hline $\begin{array}{c}\text { Worst month multipath } \\
\text { unavailability }(\%)\end{array}$ & 0,4134 & 0,179 \\
\hline
\end{tabular}

Tabel 2 merupakan perbandingan pada penggunaan repater back to back dan double flat reflector berdasarkan perancangan menggunakan pathloss 5.0. perbandingan yang dibandingkan lebih banyak daripada perbandingan link budget karena pada pathloss 5.0 hasil yang didapatkan lebih spesifik.

Passive gain yang dihasilkan juga tidak jauh berbeda dengan perbedaan pada perhitungan link budget, yaitu lebih besar nilai double flat reflector. Dengan alasan yang sama yaitu pada repeater back to back dihasilkan dari kedua antena yang dipasang secara back to back. Sedangkan pada double flat reflector, gain dihasilkan dari luas permukaan bidang reflektor sebesar 2,43 m x 3,04 m. Begitu juga dengan nilai RSL lebih besar nilai pada double flat reflector karena nilai RSL dipengaruhi oleh gain passive. Pada nilai FM juga nilai pada double flat reflector lebih besar daripada repeater back to back.

Sehingga pada Tugas Akhir ini dilihat dari tiga parameter baik antara perhitungan link budget maupun dari pathloss 5.0 mendapatkan hasil bahwa penggunaan repeater back to back antenna lebih baik daripada double flat reflector.

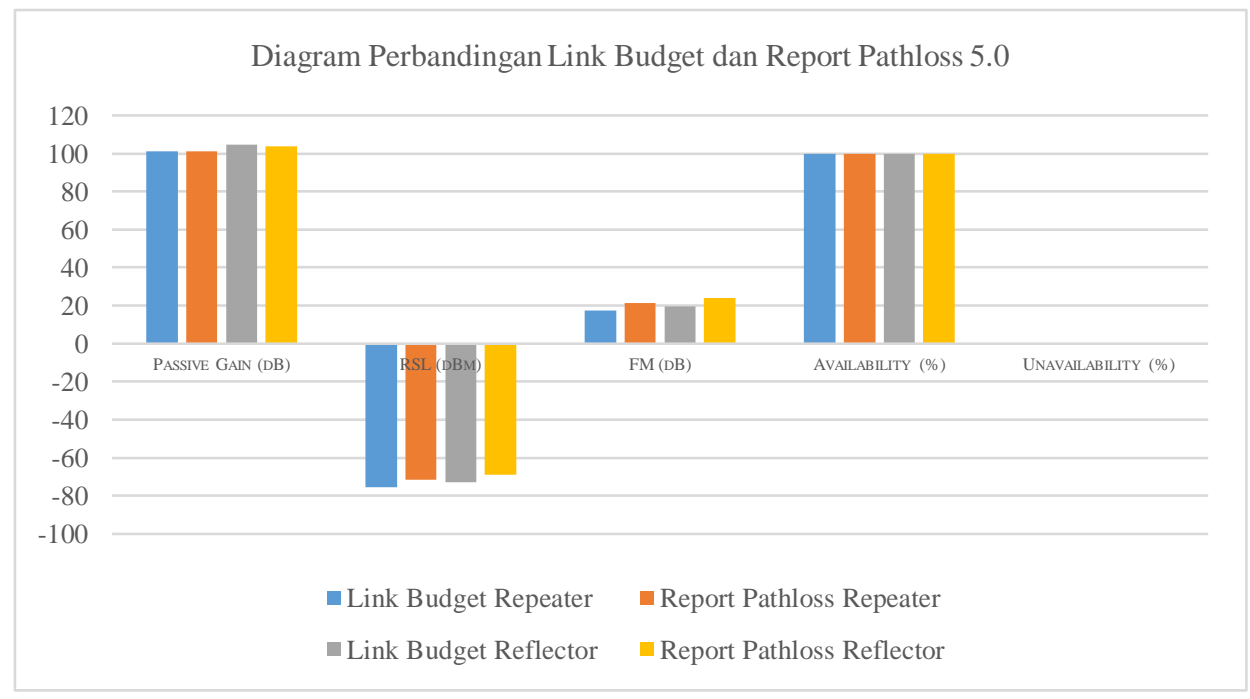

Gambar 2. Perbandingan Link Budget dan Report Pathloss 5.0 


\section{KESIMPULAN}

Berdasarkan pembahasan mengenai perbandingan penggunaan repeater back to back antenna dan double flat reflector dalam jaringan transmisi microwave didapatkan kesimpulan sebagai berikut:

1. Hasil dari nilai passive gain, RSL, FM, unavilability, dan availability perancangan jaringan transmisi microwave antara site $\mathrm{xBantaeng}$ dan $\mathrm{xSinjai}$ berbeda. Walaupun memiliki parameter-parameter yang sama seperti jarak yaitu 36,70 km, frekuensi $13 \mathrm{GHz}$, gain antena 50,94 dB, dan parameter lain yang sama.

2. Nilai passive gain antara back to back dan double flat reflector berbeda karena, pada repeater back to back dihasilkan dari kedua antena yang dipasang secara back to back. Sedangkan pada double flat reflector, gain dihasilkan dari luas permukaan bidang reflektor sebesar 2,43 m x 3,04 m

3. Nilai RSL juga mendapatkan nilai yang berbeda, dengan nilai RSL pada back to back antena lebih besar dengan nilai $-71,52 \mathrm{dBm}$ dan $-69,06 \mathrm{dBm}$ untuk double flat reflector. Perbedaan ini dipengaruhi oleh nilai gain passive, dimana untuk back to back menggunakan gaim repeater dan double flat menggunakan gain reflector. Jadi untuk nilai RSL semakin besar nilai RSL maka semakin baik kualitas layanan jaringan transmisi microwave tersebut.

4. Untuk nilai fading margin sendiri dipengaruhi oleh RSL. FM merupakan cadangan daya yang digunakan agar dapat mempertahankan level sinyal terima diatas level batas ambang atau threshold. Semakin besar nilai FM maka semakin baik pula layanan yang diberikan oleh suatu sistem, karena cadangan daya yang dihasilkan semakin besar. Jadi untuk FM penggunaan double flat reflector lebih baik daripada back to back pada karena FM yang dihasilkan double flat reflector adalah 23,94 dB, sedangkan untuk repeater back to back 21,48 dB.

5. Pada kehandalan sistem atau availability optimal bernilai diatas 99\%. Untuk kasus pada Tugas Akhir ini baik penggunaan repeater back to back maupun double flat reflector sama-sama mendapatkan nilai optimal, karena sudah berada diatas 99\%. Tetapi, penggunaan back to back antenna bernilai lebih besar daripada double flat reflector.

Pada Penelitian ini dilihat dari tiga parameter baik antara perhitungan link budget maupun dari pathloss 5.0 mendapatkan hasil bahwa penggunaan back to back antenna lebih baik daripada double flat reflector.

\section{UCAPAN TERIMAKASIH}

Penulis ingin berterima kasih kepada FTTE yang telah mendukung penulis dalam menyelesaikan penelitian ini

\section{DAFTAR PUSTAKa}

[1] I. E. Dewanti, Analisis Perbandingan Passive Repeater Back to Back dan Plane Reflector menggunakan Pathloss 5.0, 2017.

[2] R. F. H. Yang, Passive Repeater using Double Flat Reflector, pp. 36-41, 1996.

[3] A. S. Yuchintya, Analisis Perencanaan Jaringan Microwave Passive Repeater menggunakan Metode Barnett Vigants dan ITU Models, pp. 142-147, 2017.

[4] A. Hikmaturokhman, Analisa Pengaruh Interferensi Terhadap Avaibility pada Jaringan Transmisi Microwave menggunakan Software Pathloss 5.0 Studi Kasus di PT. Alita Praya Mitra, pp. 8-17, 2014.

[5] A. Hikmaturokhman, "Diktat Kuliah Gelombang Mikro," Akatel Shandy Putra, Purwokerto, 2007.

[6] R. G. Winch, Telecomunication Transmisi System Microwave, Fiber Optic, Mobile Cellular Radio, Data and Digital Multiplexing, Singapore, 1993.

[7] D. Soetamso, "Diktat Kuliah Perencanaan Transmisi Radio," Bandung, Indonesia, 1999.

[8] G. Jonatan, Rekayasa Transmisi Radio Jilid I, 2003.

[9] R. L. Freeman, Radio System Design for Telecomunications (1-100 GHz), New York, 1987.

[10] R. L. Freeman, Telecomunication Transmission Handbook, New York, 1981.

[11] I. -. S. Telkom, Handout Pelatihan Teknologi Transmisi Radio, Jakarta, 2004.

[12] A. Hikmaturokhman, Klasifikasi Link Microwave, Purwokerto: Akatel Shandy Putra Purwokerto, 2012.

[13] K. Beals, Passive Repeater for Rural ITS Communocation System.

[14] A. Hikmaturokhman, Microwave Link Budget, 2012.

[15] Pathloss, "Modul Tutorial Pathloss 5.0," Pathloss 5.0, Oktober 2012. [Online]. Available: http://www.pathloss.com/pwiki/index.php?title=Pathloss_5_-_Where to begin. [Accessed 2018]. 